\title{
Mesenchymal cystic hamartoma presenting with spontaneous pneumothorax
}

\author{
J Glezos MD FRCPC ${ }^{1}$, D Toppin MD FRCSC ${ }^{2}$, T Cooney MB FRCPC ${ }^{3}$
}

J Glezos, D Toppin, T Cooney. Mesenchymal cystic hamartoma presenting with spontaneous pneumothorax. Can Respir J $2003 ; 10(5): 280-281$.

A 53-year-old woman presented with a spontaneous right-sided pneumothorax. Computed tomography chest scan demonstrated a large bulla involving the right middle lobe. Recurrence of the pneumothorax after initial closed chest tube drainage necessitated thoracotomy and wedge resection. Histopathological examination revealed features consistent with a benign mesenchymal cystic hamartoma. Pneumothorax is a recognized complication of mesenchymal cystic hamartoma, a lesion that also has malignant potential.

Key Words: Mesenchymal cystic hamartoma; Spontaneous pneumothorax

\section{CASE PRESENTATION}

A 53-year-old female physiotherapist presented to Royal Columbian Hospital, New Westminster, British Columbia, with a spontaneous right-sided pneumothorax after a three-week history of laryngitis and bronchitis. She was a previously healthy, lifelong nonsmoker, with no history of pneumothoraxes or any other respiratory disorders. There was no history of any relevant drug or environmental exposures. Physical examination was

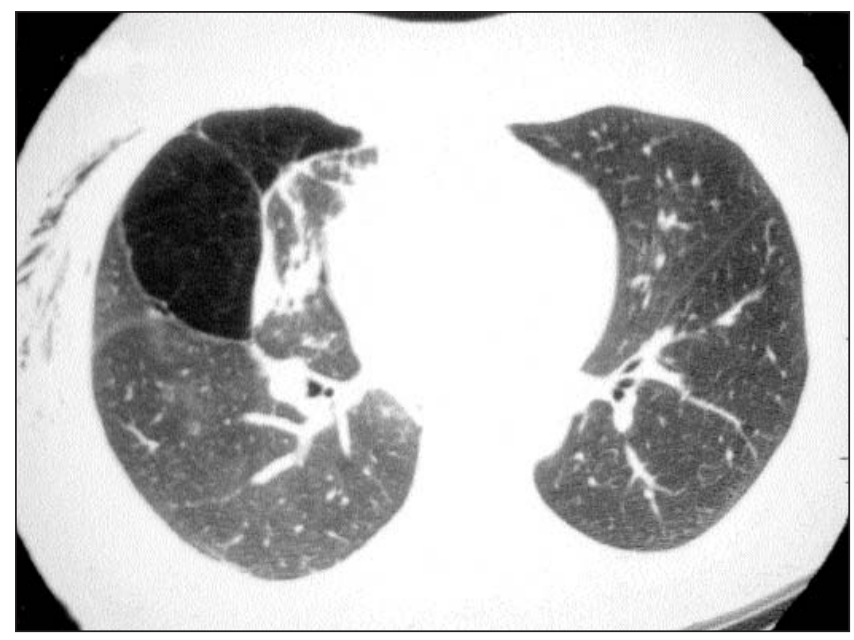

Figure 1) Computed tomography scan image from the patient. Note the large bulla involving the right middle lobe with adjacent atelectasis along the medial border. Subcutaneous emphysema is also noted, attributable to a recently treated pneumothorax

\section{Harmartome cystique mésenchymateux accompagnant un pneumothorax spontané}

Une femme de 53 ans s'est présentée avec un pneumothorax spontané du côté droit. Une tomographie par ordinateur pulmonaire a révélé une large bulle touchant le lobe moyen du poumon droit. La récurrence du pneumothorax après le drainage initial d'un drain thoracique fermé a nécessité une thoracotomie et une résection cunéiforme. Un examen histopathologique a révélé des caractéristiques correspondant à un harmatome cystique mésenchymateux. Un pneumothorax est une complication reconnue d'un harmatome cystique mésenchymateux, soit une lésion qui a également un potentiel malin. normal aside from the right-sided pneumothorax. Closed chest tube drainage was performed, but the tube dislodged accidentally after one week, with only a small right apical pneumothorax remaining. She was readmitted to hospital $48 \mathrm{~h}$ later with recurrence of a complete right pneumothorax requiring chest tube reexpansion. Computed tomography chest scan demonstrated a large bulla in the right middle lobe with a small amount of adjacent atelectasis (Figure 1). The rest of the lung fields and pleural surfaces appeared normal. Thoracotomy revealed a large bulla

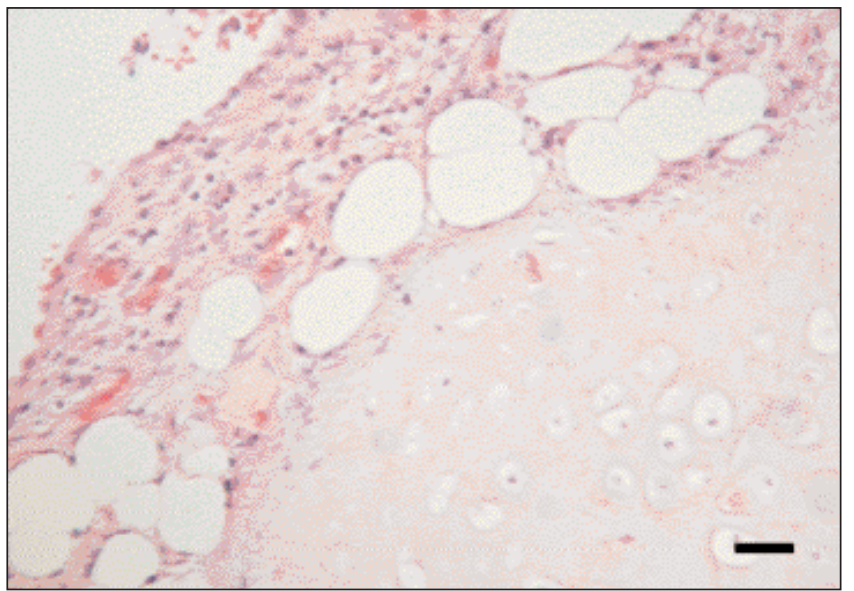

Figure 2) Medium-power photomicrograph of lung section from surgically resected specimen. Note the single layer of benign cuboidal lining cells (left edge), with adjacent adipocytes and benign cartilage comprising the lesion. (Hematoxylin and eosin stain; bar $=50 \mu \mathrm{m}$ )

\footnotetext{
${ }^{1}$ Division of Respiratory and Critical Care Medicine, Department of Medicine; ${ }^{2}$ Division of Thoracic and Vascular Surgery, Department of Surgery; ${ }^{3}$ Department of Pathology, Royal Columbian Hospital, New Westminster, British Columbia

Correspondence: Dr J Glezos, Division of Respiratory and Critical Care Medicine, Department of Medicine, Royal Columbian Hospital, 103 - 250 Keary Street, New Westminster, British Columbia V3L 5E7. Telephone 604-525-8822, fax 604-525-9470
} 
on the anterior aspect of the right middle lobe surrounded by adhesions. The bulla was centred on a very narrow stalk and was removed via wedge excision.

Pathological examination demonstrated prominent cystic change of the lung parenchyma with adjacent patchy organizing pneumonia. The cyst was lined by a single layer of benign cuboidal cells. One tissue fragment included a portion of bone with mature marrow fat, and another contained several small cartilage plates with some mature fat (Figure 2). These features were consistent with mesenchymal cystic hamartoma and superimposed organizing pneumonia.

The patient has done well postoperatively for six months with no signs of recurrence of pneumothorax.

\section{DISCUSSION}

Mesenchymal cystic hamartomas are rare tumours originating from nodules of primitive mesenchymal cells. They are considered different from ordinary hamartomas (1). These lesions grow slowly, may occur multifocally and may have a tendency to become cystic when larger than $1 \mathrm{~cm}$ in diameter (2). Larger lesions, measuring up to $10 \mathrm{~cm}$, are lined by a layer of ciliated or metaplastic squamous epithelium with an adjacent dense layer of mesenchymal cells (3). Hemorrhage from systemic arteries within the cyst wall is a potential complication, and pneumothorax or hemothorax can also occur from a subpleural cyst. A report of five adult cases noted that one patient had undergone malignant transformation (2). In another report of cystic hamartomas in childhood, two cases were found to harbour unsuspected mesenchymal sarcomas, and the authors recommended that all mesenchymal cystic hamartomas should be resected (4).

Mesenchymal cystic hamartomas should be included in the differential diagnosis of spontaneous pneumothorax, especially in older patients. They can present multifocally, and consideration should be given to surgical removal because of their malignant potential.

\section{REFERENCES}

1. Murray J, Nadel J, Mason R, Boushy H. Textbook of Respiratory Medicine, 3rd edn. Philadelphia: WB Saunders, 2001.

2. Mark EJ. Mesenchymal cystic hamartomas of the lung. N Engl J Med 1986;315:1255-9.

3. Fraser RS, Muller NL, Colman N, Pare PD. Fraser and Pare's Diagnosis of Diseases of the Chest, 4th edn. Philadelphia: WB Saunders, 1999:1373-4.

4. Hedlund GL, Bisset GS, Bove KE. Malignant neoplasms arising in cystic hamartomas of the lung in childhood. Radiology 1989;173:77-9. 


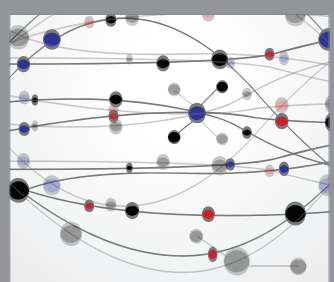

The Scientific World Journal
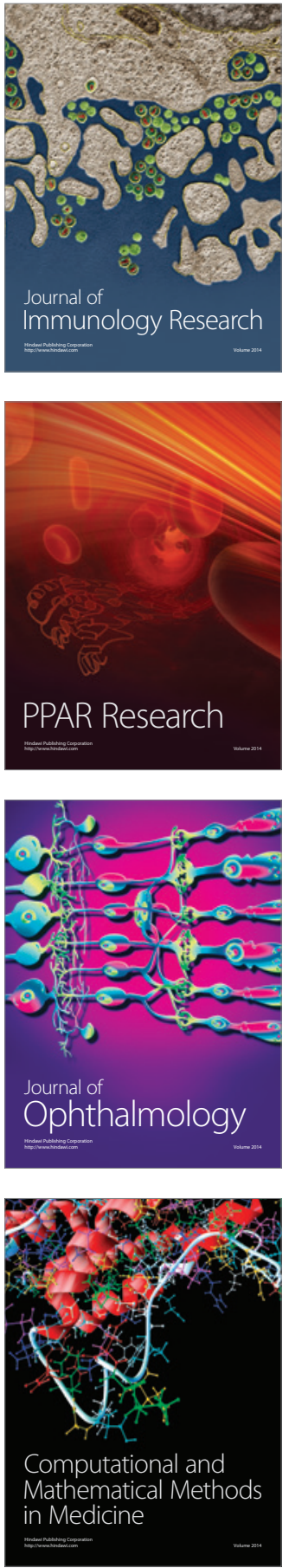

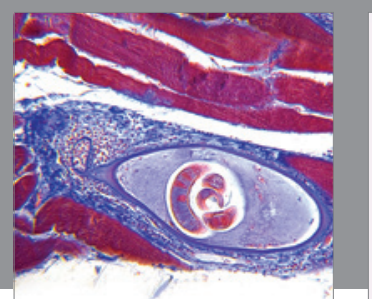

Gastroenterology Research and Practice

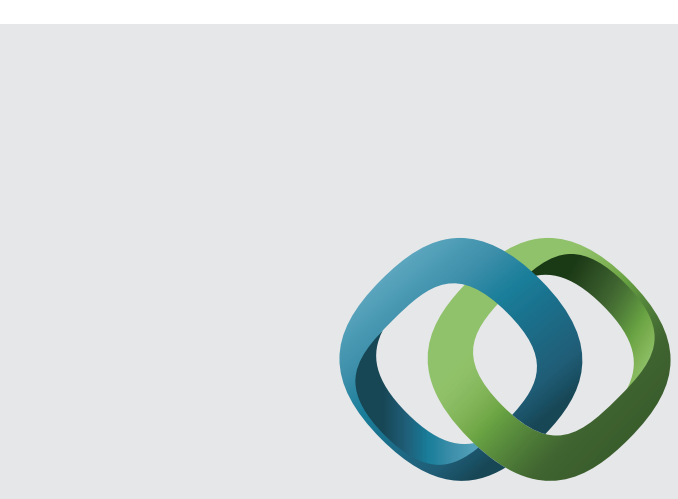

\section{Hindawi}

Submit your manuscripts at

http://www.hindawi.com
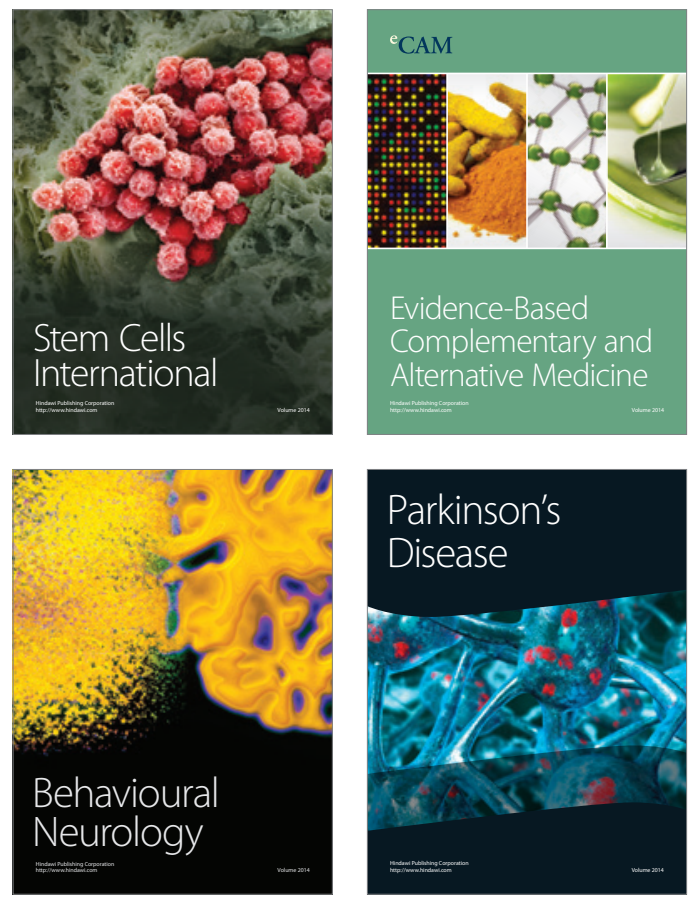
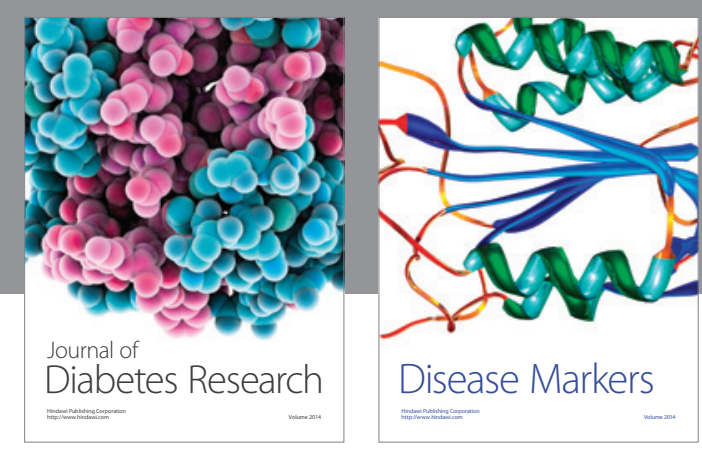

Disease Markers
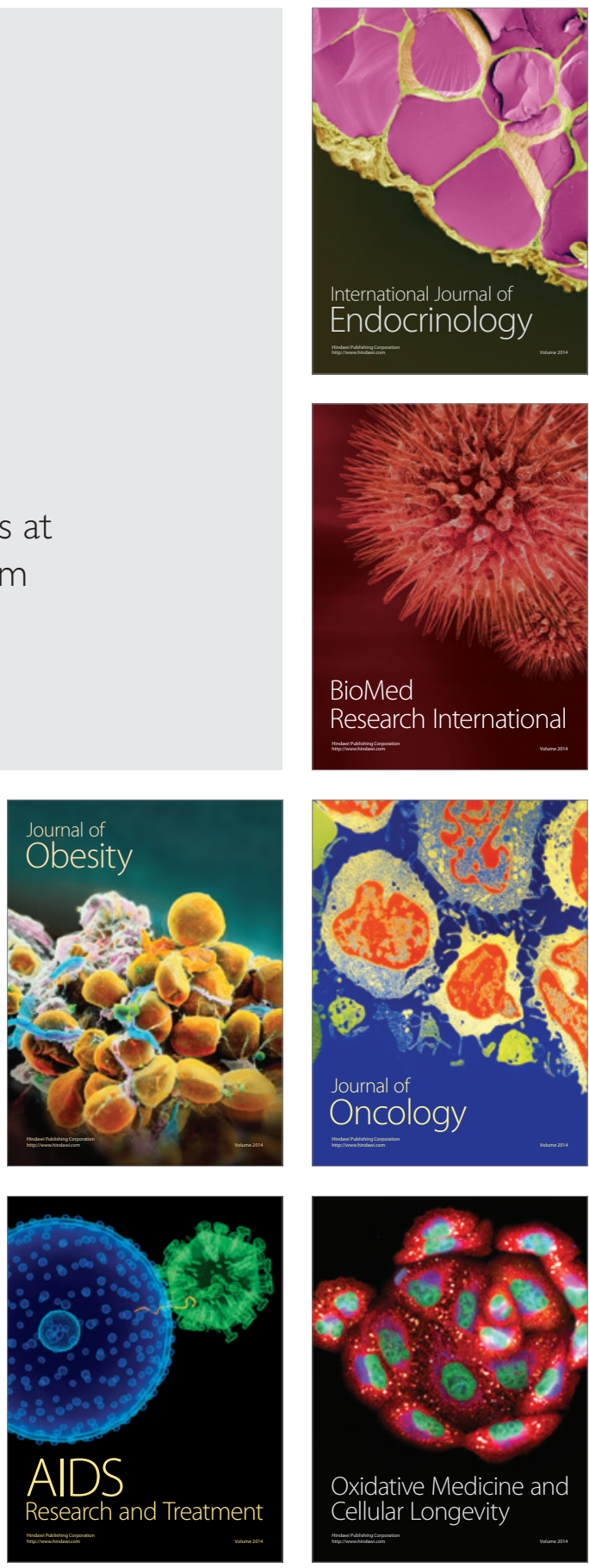